\title{
SEJARAH PERKEMBANGAN PENDIDIKAN DI PRIANGAN 1900-1942
}

\author{
Yadi Kusmayadi ${ }^{1}$ \\ Dosen Program Studi Pendidikan Sejarah FKIP-Universitas Galuh Ciamis \\ Jl. R. E. Martadinata No. 150 Ciamis, 46274 Jawa Barat
}

\begin{abstract}
ABSTRAK
Kebijakan pemerintah kolonial di Hindia Belanda (Indonesia) ketika memasuki awal abad ke-20 berubah. Diawali dengan kebijakan konservatif (kebijakan pemerintah kolonial sebelum tahun 1870, kemudian beralih ke kebijakan liberal (dengan menerapkan sistem politik pintu terbuka), dan terakhir kebijakan etis. Kebijakan politik etis ini didasari karena balas jasa dari hutang budi tanah jajahan Hindia Belanda yang telah membantu Negara induk (Belanda) secara ekonomi. Kebijakan pemerintah kolonial sebelumnya (politik etis) dinilai sangat merugikan penduduk pribumi, eksploitasi tanah dan tenaga diberlakukan ketika pemerintah kolonial masih menerapkan sistem konservatif atau tanam paksa (cultuurestelsel). Awal abad ke-20 tepatnya tahun 1902, Hindia Belanda resmi menerapkan sistem politik etis dengan memperbaharui tiga poin penting untuk kemajuan penduduk pribumi, tiga poin tersebut adalah: 1. Pendidikan, 2. Irigasi (perbaikan dalam sistem pertanian), 3. Emigrasi (perbaikan dalam masalah pemerataan penduduk). Semangat politik etis atau politik balas jasa oleh pemerintah kolonial di Hindia Belanda akhirnya melahirkan penduduk pribumi yang berpendidikan. Melalui Pendidikan, penduduk pribumi akhirnya mengetahui hal-hal yang dipelajari oleh orang-orang Belanda. Lebih jauhnya para penduduk pribumi yang berfikiran kritis akhirnya melahirkan satu kelas sosial baru di Hindia Belanda yang mengingkan sebuah kemerdekaan. Pentingnya perkembangan sejarah pendidikan pada masa politik etis ini menjadi sebuah dasar dari perubahan tatanan sosial di Hindia Belanda. Lahirnya kelas intelektual pribumi membuat perjuangan menuju kemerdekaan tidak lagi menggunakan segala bentuk kekerasan, angkat senjata dan peperangan. Perjuangan intelektual pribumi akhirnya berubah kedalam bidang politik dan pendidikan.
\end{abstract}

\section{Kata Kunci: Politik Etis, Pendidikan, Perubahan Sosial}

\begin{abstract}
The policy of the colonial government in the Indies (Indonesia) when entering the beginning of the 20th century changed. Beginning with a conservative policy (the policy of the colonial government before 1870, then turning to liberal policy (by applying a system of "politik pintu terbuka"), and the last ethical policy (politik etis). The policy of ethical politics is based on the repayment of Dutch East Indies colonial debt which helped the State (Dutch) economics The policy of the previous colonial government (ethical politics) was considered to be very detrimental to the indigenous population, the exploitation of land and labor came into force when the colonial government still adopted a conservative system or cultivation (cultuurestelsel). The early 20th century was precisely 1902, the Indies The Netherlands officially adopts an ethical political system by updating three important points for the progress of the indigenous population, three points are: 1. Education, 2. Irrigation (improvement in the agricultural system), 3. Emigration (improvement in the issue of equality of the population). Political retaliation by the colonial government in the Indies of Beland A finally gave birth to an educated native population. Through Education, the indigenous population finally learned the things that the Dutch learned. Furthermore, the native inhabitants of critical thinking eventually gave birth to a new social class in the Dutch East Indies which eased a freedom. The importance of the development of the history of education in this period of ethical politics became the basis of the change of social order in the Indies. The birth of the indigenous intellectual class made the struggle for independence no longer using all forms of violence, arms and fighting. Indigenous intellectual struggle has finally changed into politics and education.
\end{abstract}

\section{Keywords: Ethical Policy, Education, Social Change}

\footnotetext{
Penulis Koresponden

E-mail address: yadikusmayadi@unigal.ac.id doi: http://dx.doi.org/10.25157/ja.v4i2.908
} 


\section{PENDAHULUAN}

Pada tahun 1901 Ratu Wilhelmina berpidato didepan parlemen Belanda. ia menjelaskan bahwa Belanda mempunyai utang kehormatan kepada Hindia Belanda. Semangat ini (etis) sudah ada ketika permasalahan kemanusiaan terjadi. Kecaman karena persoalan kemanusiaan ini dilakukan oleh orang-orang Belanda yang berfikir humanisme ${ }^{2}$. Politik etis berakar kepada masalah kemanusiaan dan keuntungan ekonomi. Kecaman-kecaman atau bentuk kritik terhadap sistem pemerintahan kolonial pertama kali (kemungkinan) dilakukan oleh E. Douwes Dekker ${ }^{3}$.

“.... Para pemimpin Lebak ${ }^{4}$ ! Kita semua ingin menjalankan kewajiban kita! Namun seandainya ada diantara kita yang melalaikan tugas demi memperoleh keuntungan, menjual keadilan demi uang, atau yang mengambil kerbau dari orang miskin dan buah-buahan milik mereka yang kelaparan...siapa yang seharusnya menghukum mereka? Jika salah satu dari anda mengetahuinya, dia akan mengehentikannya. Maka regen tidak lagi mengalami hal-hal seperti ini di Kabupatennya. Dan saya juga akan menghentikannya semampu saya. Namun jika anda, maupun Adipati, maupun saya tidak mengetahuinya. Para pemimpin Lebak! Lalu siapa yang akan melaksanakan keadilan di Banten Selatan? Dengarkan saya, dan saya akan memberitahu anda bagaimana keadilan akan dilaksanakan nanti.... (Multatuli. 2014: 143)".

Penggalan diatas adalah roman yang ditulis oleh Douwes Dekker yang berjudul Max Havelaar dengan menggunakan nama samaran Multatuli pada tahun 1860. Semenjak buku pertama yang membuka mata dunia mengenai buruknya sistem kebijakan pemerintah kolonial di tanah jajahan, suara-suara atau dukungan untuk perubahan di Hindia Belanda semakin banyak. Pemikiran untuk mengurangi penderitaan rakyat di Hindia Belanda yang tertindas akibat sistem pemerintah kolonial telah hadir dibenak para pegawai kolonial baru. Pada akhir abad ke-19 para pegawai kolonial baru berangkat menuju Hindia Belanda dengan membawa Max Havelaar di dalam kopor mereka da nisi novel itu dikepala mereka (Ricklefs. 2008: 327-328).

Pada tahun 1870 awalnya dianggap sebagai titik balik kebijakan dalam sejarah politik kolonial Belanda. Satu-satunya alasan mengapa kebijakan tahun 1870 menjadi peletak dasar kebijakan yang bersifat liberal adalah undang-undang agraria yang disahkan. Pengambilalihan tanah penduduk pribumi sudah menjadi larangan, akhirnya orang-orang asing diperbolehkan menyewa tanah pertanian dalam jangka waktu lima tahun (Kartodirdjo. 2014: 30). Ketentuan ini dimaksudkan untuk mencegah timbulnya kekuasaan yang merampas hak milik atas tanah secara semena-mena. Pada hakikatnya ide-ide tentang humanism sudah dilakukan pada era kebijakan pemerintah liberal, namun ketentuan selanjutnya dalam kebijakan liberal ini ialah pemberian kuasa atas siapapun (pengusaha swasta) untuk menggunakan tanah penduduk pribumi.

Sejatinya dalam sistem gilda atau agraria, tanah dan tenaga kerja merupakan satu kesatuan yang utuh. Kedua unsur (tanah dan pekerja) terjalin pada struktur kekuasaan setempat, mereka yang menguasai tanah dengan lahan perkebunan yang luas dan atau yang mempunyai pabrik dapat menggunakan tenaga penduduk secara sewenang-wenang. Tenaga kerja yang digunakan pada masa kebijakan liberal ini diperoleh atas dasar kontrak. Meskipun dengan sistem tenaga kerja diperoleh dengan kontrak, tuntutan-tuntutan yang melampaui batas tidak dapat dicegah, Karena rakyat kecil tidak berdaya

\footnotetext{
${ }^{2}$ Humanisme adalah aliran filsafat yang bertolak dari faham antropomorfisme. Humanisme akhirnya menjadi istilah umum untuk jalan yang terbuka atau jalan keluar dari masalah-masalah atau isu yang berhubungan dengan manusia, Lihat pula, Sartre. Eksistensialisme \& Humanisme, terj: Murtanto. Yogyakarta. Pustaka Pelajar: 2002, hal 103.

${ }^{3}$ Edward Douwes Dekker adalah anggota Dewan Pengawas Keuangan Kolonial yang tempatkan di Batavia pada tahun 1840. Pada tahun 1842 ia dipindahkan ke Sumatra (Sumatra Barat, dan Mandailing Natal Sumatra Utara) untuk bertugas sebagai pengawas keuangan kolonial (kontrolir). Ditahun yang sama E. Douwes Dekker dipindahkan ke Lebak, Banten. Disana selama bertugas, ia menolak tegas sistem pemerintahan kolonial. Ketidakadilan, perampasan serta eksploitasi penjajahan merupakan kritik yang dilakukan olehnya. Ia menulis sebuah roman yang berjudul Max Havelaar dengan menggunakan nama samara Multatuli.

${ }^{4}$ Sebuah wilayah Kabupaten yang kini berada di Provinsi Banten.
} 
menghadapi kepala-kepala mereka atau pengusaha-pengusaha Belanda. Sistem yang baru itu mempunyai akibat yang menguntungkan, akan tetapi mereka tidak dapat menduga konsekuensi-konsekuensi lainnya, bahwa akhirnya kebebasan berusaha, sebagai cita-cita sosial dan ekonomi, hamper-hampir menjadi kata lain dari eksploitasi kapitalis (Kartodridjo. 2014: 30 \& Furnivall. 1948: 225).

Kehadiran Undang-undang agraria tahun 1870 telah membawa perubahan yang sangat signifikan di Hindia Belanda. Hal ini terbukti dengan diberlakukkannya penyewaan tanah di daerah-daerah Pulau Jawa sampai 75 tahun. Pemerintah kolonial memberikan konsensi kepada perusahaan-perusahaan swasta untuk menggarap tanah, pemerintah kolonial memberikan kebebasan dan jaminan keamanan kepada perusahaan-perusahaan perkebunan untuk menanamkan modal pada sektor perburuhan (Ricklefs. 2008: 271). Beberapa komoditi yang menjadi keunggulan pemerintah kolonial dalam perkembangan kebijakan sebelum tahun 1870 dan sesudahnya di Priangan adalah teh, kopi, karet dan kelapa. Di Priangan, pemerintah Hindia Belanda mewajibkan kerja pengabdian kepada para tenaga kontrak. Residen Priangan pada tahun 1867 memberitahukan kepada para Bupati, Kepala Distrik, dan kepala dibawahnya bahwa pertahun dari setiap wajib kerja itu hendaknya dibagi seadil mungkin (Koloniaal Verslag. Th. 1869-1870: 309). Enklaar menjelaskan, rincian yang dibuat oleh Gubernur Jendral Van Den Bosch pada tahun 1830 di Priangan dari jumlah penduduk 471.949 jiwa 14.119 keluarga dikerahkan untuk tanaman kopi dan tiga puluh tahun kemudian, ketika penduduk naik sampai 829.525 jiwa, dari total 108.816 keluarga petani 89.000 diantaranya bekerja untuk budidaya tanaman kopi (Enklaar. 1871: 133).

Sebagai bentuk implentasi Keputusan yang keluarkan oleh Kerajaan Belanda, politik etis akhirnya dilaksanakan. Semangat ideologi humanism yang berada di tengah-tengah Parlemen Belanda mewarnai perubahan dalam kebijakan ke tanah Hindia Belanda. Politik Etis adalah upaya meningkatkan kesejahteraan penduduk pribumi yang dirumuskan diakhir abad ke-19. Semenjak cultuur stelsel dijalankan, pemerintah Hindia Belanda berhasil memberikan uang ke Negri Belanda kurang lebih 10.000.000 sampai 40.000.000 gulden setiap tahun. Kebijakan ini disebut dengan kebijakan sistem keuntungan bersih (batiq slot). Keuntungan bersih yang diterima terakhir oleh Negeri Belanda pada tahun 1877 senilai 825.000.000 gulden (Kartodirdjo. 2014: 31-32).

Di Parlemen Belanda sendiri timbul pro dan kontra akan kebijakan yang akan merubah paradigma penduduk pribumi. Beberapa kalangan ingin rakyat (penduduk pribumi) di Hindia Belanda ikut menikmati keuntungan dari kesejahteraan yang selalu orang Belanda rasakan, kalangan ingin tetap mengeksploitasi tanah dan tenaga penduduk pribumi untuk kepentingan mereka sendiri.

Akhirnya berdasarkan Keputusan Kerajaan (Koninklijk Besluit) yang dikeluarkan pada tanggal 21 September 1866, Lembaran Negara Hindia-Belanda (Staatsblad van Nederlandsch-Indië) Tahun 1866 No. 127 didirikan empat departemen pemerintahan umum. Salah satunya adalah Departemen Pendidikan yang menyatu dengan Ibadah dan Industri Kerajinan (Departement van Onderwijs, Eredienst en Nijverheid/ OEN) oleh Menteri Urusan Daerah atau Tanah Jajahan (Minister van Koloniën) I.D Fransen de Putte yang menjabat pada tahun 1863-1866 dan 1872-1874 di Belanda (Anrooij. 2014: 107). Hal ini dilaksanakan menjadi sebuah kebijakan karena ingin memajukan Pendidikan di Hindia Belanda secara tersistematis. Fransen (Mentri Urusan Tanah Jajahan) ini meyakini, guna meningkatkan kebutuhan tenaga yang terlatih, baik di dalam usaha atau sistem pemerintahan kolonial akan sangat banyak dibutuhkan. Jika ada lebih banyak sekolah didirikan di Hindia Belanda, maka tanah jajahan ini akan mengurangi ketergantungannya kepada para tenaga kerja terdidik dari Belanda yang mahal (Anrooij. 2014. 107).

Perkembangan di dalam sistem Pendidikan pun akhirnya memiliki dampak positif kepada kesejahteraan penduduk pribumi di Hindia Belanda, lebih jauhnya proses pergerakan politik kemerdekaan dikemudian hari berawal dari para pelajar-pelajar terdidik kalangan bumi putra. Akhirnya kebijakan politik etis yang menitik beratkan kepada perbaikan dalam tiga hal yaitu, Irigasi (sistem pengairan), edukasi (pendidikan) dan emigrasi (penyebaran penduduk) dilaksanakan pada tahun 1901 setelah pidato Ratu Wilhelmina di depan Parlemen Belanda. Dalam segi politik, kebijakan politik etis ini didukung oleh tiga golongan di Parlemen Belanda, pertama golongan agamawan, kedua golongan sosial-demokrat dan ketiga golongan 
etis atau golongan yang menjunjung tinggi rasa kemanusiaan. Pada tahun 1902, tepatnya setahun politik etis ini disahkan oleh Menteri Urusan Daerah Jajahan Alexander W.F Idenburg yang menjabat di Hindia Belanda pada tahun 1902, 1908, 1918 dan menjabat Gubernur Jendral Hindia Belanda pada tahun 1909-1916, mempraktikan pemikiran-pemikiran politik etis (Ricklefs. 2008. 328).

\section{METODE PENELITIAN}

Metode penelitian yang digunakan dalam penulisan jurnal ilmiah ini ialah metode sejarah. Metode sejarah adalah suatu usaha atau cara untuk mempelajari dan mengenali fakta-fakta serta menyusun simpulan tentang sebuah peristiwa penting pada masa lalu. Tujuan dari metode penelitian sejarah ialah membuat rekonstruksi masa lalu secara tersistematis dan objektif (Gottschalk. 2008 \& Garraghan. 1957: 37). Tahapan penelitian dalam metode sejarah sendiri terbagi menjadi empat tahapan kerja. Tahap pertama ialah heuristik. Heuristik adalah tahapan awal yang dilakukan ketika sudah menentukan topik penelitian. Heuristik sendiri ialah proses mencari, menemukan dan menghimpun sumber-sumber sejarah yang terkait dengan pokok permasalahan. Heuristik dengan proses pencarian sumber fokus kepada sumber tertulis (studi literatur), sumber benda dan lisan. Sumber tertulis berupa arsip, sumber resmi tercetak, dokumen, buku dan lain-lain dilakukan untuk memperoleh data yang sesuai dengan penulisan jurnal ilmiah ini. Sumber tertulis berupa arsip, sumber resmi tercetak, dokumen ditelusuri di Arsip Nasional Republik Indonesia (ANRI). Pencarian sumber primer atau sumber yang sezaman yang berbentuk sumber resmi tercetak, surat kabar dan buku dilakukan di beberapa perpustakaan, antara lain: Perpustakaan Nasionali Republik Indonesia (PNRI), Badan Perpustakaan dan Arsip Daerah (BAPUSIPDA) Jawa Barat, Perpustakaan Ajip Rosidi di Bandung, Perpustakaan Batu Api Jatinangor dan Perpustakaan Fakultas Ilmu Pendidikan dan Ilmu Keguruan (FKIP) di Universitas Galuh.

Di Jakarta, tepatnya di Arsip dan Perpustakaan Nasional pencarian sumber tertulis dikhususkan untuk pencarian sumber sezaman, seperti lembaran negara (staatsblad, verslag), dan surat kabar yang terbit awal abad 20 dan akhir abad ke-19 dilakukan di Perpustakaan
Nasional. Di Perpustakaan Ajip Rosidi, BAPUSIPDA, Perpustakaan Batu Api Jatinangor dan Perpustakaan FKIP Universitas Galuh dikhususkan kepada pencarian sumber sekunder dan buku-buku yang mendukung penelitian jurnal ilmiah tentang sejarah perkembangan Pendidikan di Priangan yang dimulai pada tahun 1900 samai 1942. Setelah Heuristik tahapan dalam metode penelitian sejarah adalah kritik sumber.

Kritik Sumber dalam metode sejarah terbagi menjadi dua, yaitu kritik ekstern dan kritik intern. Kritik ekstern bertujuan untuk menentukan otentisitas sumber dengan cara memberikan penilaian kepada kondisi fisik sumber tersebut, seperti kertas, tinta, huruf, watermark, stempel dan sebagainya. Kritik intern dilakukan dengan menilai sumber dan membandingkan data yang ada, artinya data yang berada di dalam sumber tersebut dibandingkan dengan sumber lainnya.

Tahap ketiga dalam metode penelitian historis yang akan digunakan dalam penelitian jurnal ilmiah ini adalah interpretasi. Interpretasi adalah proses menafsirkan berbagai fakta menjadi sebuah rangkaian yang logis. Pada tataran oprasionalnya langkah interpretasi ini dilakukan secara sistematis dan analitis dengan mengurai fakta dan dilakukan secara sintesis yakni menghimpun fakta. Pemahaman secara verbal tidak memadai untuk menginterpretasikan informasi yang terkandung di dalam sumber sejarah. Faktra yang diperoleh diinterpretasikan baik secara verbal, teknis, logis, faktual dan psikologis. Dengan demikian, interpretasi yang dhasilkan dapat dipahami secara menyeluruh dan mendalam.

Tahap selanjutnya adalah tahapan terakhir dalam penulisan sejarah menggunakan metode historis, Historiografi. Historiografi adalah tahapan penulisan sejarah. Fakta yang telah diinterpretasikan kemudian dituliskan dalam penulisan yang sistematis dan kronologis. Historiografi yang akan dihasilkan dibagi menjadi beberapa pembahasan, yang secara keseluruhan merupakan satu kesatuan yang utuh. Dengan menggunakan metode sejarah, panduan bagaimana teknis penelitian jurnal ilmiah ini dapat dikerjakan secara efektif dan akurat. Efektif dalam pengertian tahapan demi tahapan dikerjakan dengan terperinci. Akurat dalam pengertian hanya sumber yang telah menjadi fakta sejarah yang dapat dijadikan bahan penulisan jurnal ilmiah ini. Selain itu, unsur diakronis yang menunjukan sejarah, sebagai 
ilmu tentang berfikir dalam waktu sangat diperhatikan.

Pada penulisan jurnal ilmiah ini teori atau pendekatan secara teoritis untuk membangun sebuah narasi sejarah dalam eksplanasi dijelaskan tidak secara terperinci. Pendekatan dalam penelitian jurnal ilmiah ini menggunakan konsep-konsep Pendidikan yang digunakan sebagai pendekatan untuk penelitian sejarah Pendidikan di Priangan pada masa kolonial.

\section{HASIL PENELITIAN DAN PEMBAHASAN}

\section{Sistem Pendidikan Sebelum Politik Etis}

Pada tahun 1899 terbit sebuah artikel yang ditulis oleh Van Deventer di majalah De Gids dengan judul “Hutang Kehormatan”. Didalam artikel tersebut Van Deventer mengemukakan bahwa keuntungan yang diperoleh dari Hindia Belanda selama ini hendaknya dibayar kembali dari perbendaharaan negara. Pada tahun 1901 hasil dari pemikiran Van Deventer akhirnya tertuang dalam pidato Ratu Belanda yang isinya kurang lebih seperti ini:

"Sebagai negara Kristen, Nederland berkewajiban di kepulauan Hindia Belanda untuk lebih baik mengatur kedudukan legal penduduk pribumi, memberikan bantuan pada dasar yang tegas kepada missi Kristen, serta meresapi keseluruhan tindak laku pemerintah dengan kesadaran bahwa Nederland mrmpunyai kewajiban moral untuk memenuhinya terhadap penduduk di daerah itu. Berhubungan dengan itu, kesejahteraan rakyat Jawa yang merosot memerlukan perhatian khusus. Kami menginginkan diadakannya penelitian tentang sebab musababnya".

Peristiwa itu dipandang sebagai bentuk ekspresi dari ide baru dan praktik politik yang kemudian kita kenal dengan nama Politik Etis atau Politik Balas Jasa. Prinsip dari politik etis ini kemudian sangat bertentangan dengan politik eksploitasi materi pada masa pemerintahan kolonialisme yang telah lalu. Politik etis akhirnya menonjolkan sikap kewajiban moral bangsa yang mempunyai kebudayaan tinggi terhadap bangsa yang tertindas (Nasution. 1987: 15). Meskipun secara sah dan dibentuk lembaga negara yang khusus menangani Pendidikan di Hindia Belanda. Pendidikan jauh sebelum politik etis dilaksanakan sudah dijalankan. Seperti contoh, di Hindia Belanda pada tahun
1607 pernah mendirikan sekolah di Ambon untuk anak-anak Indonesia. Tujuan utama dari Pendidikan di sekolah tersebut adalah menghapuskan ajaran katolik dengan cara menyebarkan agama protestan dan calivinis, jumlah sekolah modern pertama yang didirikan di Ambon ini kemudian cepat bertambah. Selanjutnya pada tahun 1632 di Ambon telah berdiri 16 sekolah dan pada tahun 1645 jumlah sekolah bertambah menjadi 33 sekolah dengan jumlah murid 1.300. Namun perkembangan selanjutnya memasuki abad ke-18 perkembangan Pendidikan menurun (Nasution. 1987: 4-5).

Sekolah pertama di Pulau Jawa berada di Jakarta. Pada tahun 1630 VOC membuka sekolah dan mendidik anak Belanda dan Jawa. Hal ini dilaksanakan karena VOC membutuhkan para pekerja yang kompeten. Selanjutnya, memasuki abad ke-18 daerah kekuasaan Pemerintah Hindia Belanda semakin meluas, perdagangan yang dikelola oleh pemerintah Hindia Belanda semakin besar, akhirnya dibutuhkan pula kewajiban dan tanggung jawab yang besar. Maka untuk melancarkan usahanya itu, pemerintah Hindia Belanda sangat membutuhkan bantuan tenaga kerja yang terdidik. Perubahan mendasar dari sistem Pendidikan sebelum politik etis dilakukan oleh Daendels tatkala pergantian sistem pemerintahan di Hindia Belanda yang awalnya dikuasai oleh VOC kemudian diambil alih langsung oleh pemerintahan Hindia Belanda yang terpusat ke Negeri Belanda. Daendels melakukan perubahan secara mendasar dalam sistem Pendidikan di Hindia Belanda sebagaimana berikut:

1) Pendidikan berdasarkan agama Kristen (yang terikat dengan gereja) ditinggalkan.

2) Sesuai dengan orientasi Daendels yang berkisar kepada permasalahan pertanahan dan strategi militer, maka pada tahun 1806 dibuka sekolah pertama, yaitu Sekolah Artileri di Meester Cornelis (Jatinegara-Jakarta).

3) Pada tahun 1808 Daendels memerintahkan kepada para Bupati di Jawa untuk mendirikan sekolah-sekolah di tiap-tiap distrik, yang memberikan Pendidikan berdasarkan adat-istiadat, undang-undang dan pokok-pokok pengertian keagamaan (Islam). Perintah tersebut ternyata tidak sempat dilaksanakan, sebab tiga tahun 
kemudian (1811) masa pemerintahan Daendels berakhir karena kekuasaan di Pulau Jawa jatuh ke tangan Inggris (Raffles). Namun demikian, perintah Daendels itu mengandung arti penting, yaitu pemerintah untuk pertama kalinya mengakui bahwa pemberian pengajaran kepada rakyat adalah tugas dan kewajiban pemerintah dan pengajaran itu tidak terbatas kepada kelompokkelompok masyarakat tertentu saja, melainkan merata di semua lapisan masyarakat. Pada tahun 1808 juga, Daendels mendirikan sebuah Sekolah Angkatan Laut di Semarang.

4) Pada tahun 1809 , untuk pertama kalinya diselenggarakan Pendidikan bidan sebagai bagian dari usaha pemeliharaan kesehatan rakyat. Pengajaranya adalah para dokter yang berada di Batavia, dengan menggunakan Bahasa pengantar Bahasa melayu.

5) Pada tahun 1809 Daendels memerintahkan kepada bekas Sultan Cirebon agar di Cirebon didirikan tiga buah sekolah dari gadis (ronggeng) yang berada di bawah tanggungan Sultan. Pendidikan disekolah ini terutama diberikan kepada anak-anak perermpuan dari keluarga tidak mampu. Disekolah tersebut tidak dipungut biaya kecuali dari anak-anak orang kaya. Lama belajarnya 4 tahun. Pelajaran yang diberikan adalah menari, menyanyi, membaca dan menulis. Pada hakikatnya sekolah ini didirikan, karena upaya mendemoralisasikan pemuda-pemudi Indonesia, karena tujuan utamanya adalah menjauhkan semangat heroism dan patriotisme bangsa Indonesia dan mereka tidak lagi menaruh perhatian kepada agitasi politik (Ekadjati, 1986: 40-41).

Perubahan dalam sistem Pendidikan yang dilakukan oleh Daendels di Hindia Belanda tidak sepenuhnya terlaksana. Salah satu faktor yang menjadi kegagalan pemerintahan Daendels pada sistem Pendidikan ini adalah tidak adanya biaya khusus untuk pembinaan pendidikan dan pengajaran, ditambah dengan peralihan kekuasaan dari tangan Daendels kepada Inggris Gubernur Jendral Sir Thomas Stamford Raffles. Tahun 1811-1816 adalah periode Raffles yang terfokus kepada kebijakan ekonomi. Kerja rodi dan perbudakan yang dilaksanakan pada masa pemerintahan Daendels segera dihapuskan dengan kebijakan ekonomi yang humanis. Raffles mewajibkan pajak kepada para penduduk pribumi. Konsentrasi Raffles kepada permasalahan ekonomi di Hindia Belanda, sektor pendidikan akhirnya terabaikan. Ketika pemerintahan Raffles berkuasa, sekolah-sekolah yang didirikan pada masa pemerintah Daendels keadaannya sangat memprihatinkan, pada masa akhir jabatan pemerintahan Raffles sekolahsekolah yang didirikan pada masa pemerintahan Daendels sudah tidak ada lagi.

Pemerintahan selanjutnya setelah Raffles akhirnya membuat besluit (surat keputusan Kerajaan) pada tahun 1866. Surat keputusan ini adalah pendirian empat departemen pemerintahan umum, salah satunya adalah Departemen van Onderwijs, Eredienst en Nijverheid/OEN (Departemen Pendidikan, Ibadah dan Industri Kerajinan). Pembentukan departemen itu akhirnya dapat mengakhiri situasi sebelumnya yang kadang memposisikan dan mengabaikan Pendidikan dalam sistem pemerintahannya. Campur tangan dalam hal Pendidikan di Jawa dan Madura akan menjadi urusan dari para kepala pemerintah daerah. Di tingkat pusat soerang hoofdcommissie van Onderwijs (Kepala Komisi Pendidikan) menjalankan tugasnya dibawah pimpinan seorang anggota Raad van Indie (Dewan Hindia), sementara itu pada tahun 1864 diangkat seorang inspektur pendidikan pribumi (Anrooij. 2014: 107).

Pada tahun 1864 inspektur Pendidikan pribumi mengeluarkan undang-undang yang mengatur Pendidikan model barat bagi penduduk pribumi. Dalam perkembangan sistem Pendidikan yang bilingual dan dualistis. Pendidikan yang menggunakan Bahasa pengantarnya Bahasa Belanda hanya diperuntukkan bagi orang-orang Eropa dan kalangan atas masyarakat pribumi: Pendidikan ini diberikan di Europese Largere School (ELS), Hollandsche Inlandsche School (HIS) dan Hollandsche-Chinesse School (HCS). Selanjutnya ada Pendidikan berbahasa pribumi untuk kaum menengah dan sejumlah masyarakat lainnya: untuk kategori pertama ada standaardschool (Sekolah Standar) dan desaschool (Sekolah Desa). Melalui sistem Pendidikan seperti itu, perkembangan sekolah di Hindia Belanda dapat dibedakan menjadi empat kategori, yaitu 1. Sekolah Eropa yang sepenuhnya menerapkan sistem sekolah negeri 
Belanda, 2. Sekolah pribumi dengan pengantar Bahasa Belanda, 3. Sekolah pribumi dengan pengantar Bahasa daerah, 4. Sekolah dengan menerapkan sistem pribumi (Falah. 2010: 194).

\section{Sistem Pendidikan di Priangan}

Di Tasikmalaya, secara umum sistem Pendidikan yang Nampak dapat dibedakan menjadi dua kategori. Pertama Pendidikan non formal yakni Pendidikan yang dilaksanakan di lingkungan pesantren dan Pendidikan formal yaitu Pendidikan model barat yang diperkenalkan oleh pemerintah kolonial. Dalam konteks Pendidikan non formal, di Tasikmalaya lembaga pesantren sangat berkembang. Hal ini dikarenakan mayoritas penduduk Tasikmalaya beragama Islam, bagi umat Islam tugas mencari ilmu sangat diejawantahkan dalam praktik kehidupan sehari-hari. Maka di Tasikmalaya sekitar tahun 1873 kurang lebih 100 lembaga pesantren telah berdiri. Pesantren tertua di Tasikmalaya adalah Pesantren Riyadlul Ulum Wadda'wah yang terletak di kampung Condong, Desa Condong, Kecamatan Cibeureum. Pesantren ini didirikan sekitar awal abad ke-19 oleh Kyai Nawawi yang berasal dari Rajapolah. Tanah yang dipergunakan untuk mendirikan Pesantren itu, merupakan wakaf dari Pangeran Kornel, Bupati Sumedang (Miftah. 2010: 195). Selain pesantren, di Tasikmalaya lembaga Pendidikan yang diperkenalkan oleh pemerintah kolonial. Sebagaimana telah dijelaskan bahwa sistem pendidikan kolonial di Hindia Belanda baik sebelum politik etis maupun setelah politik etis berlangsung pada pertengahan abad ke-20 bersifat dualistis. Pemerintah Hindia Belanda membuka dua jenis sekolah untuk penduduk pribumi. Sekolah kelas satu (eerste klasse school) dan sekolah kelas dua (tweede klasse school).

\section{Bagan : Sistem Pendidikan Hindia Belanda}

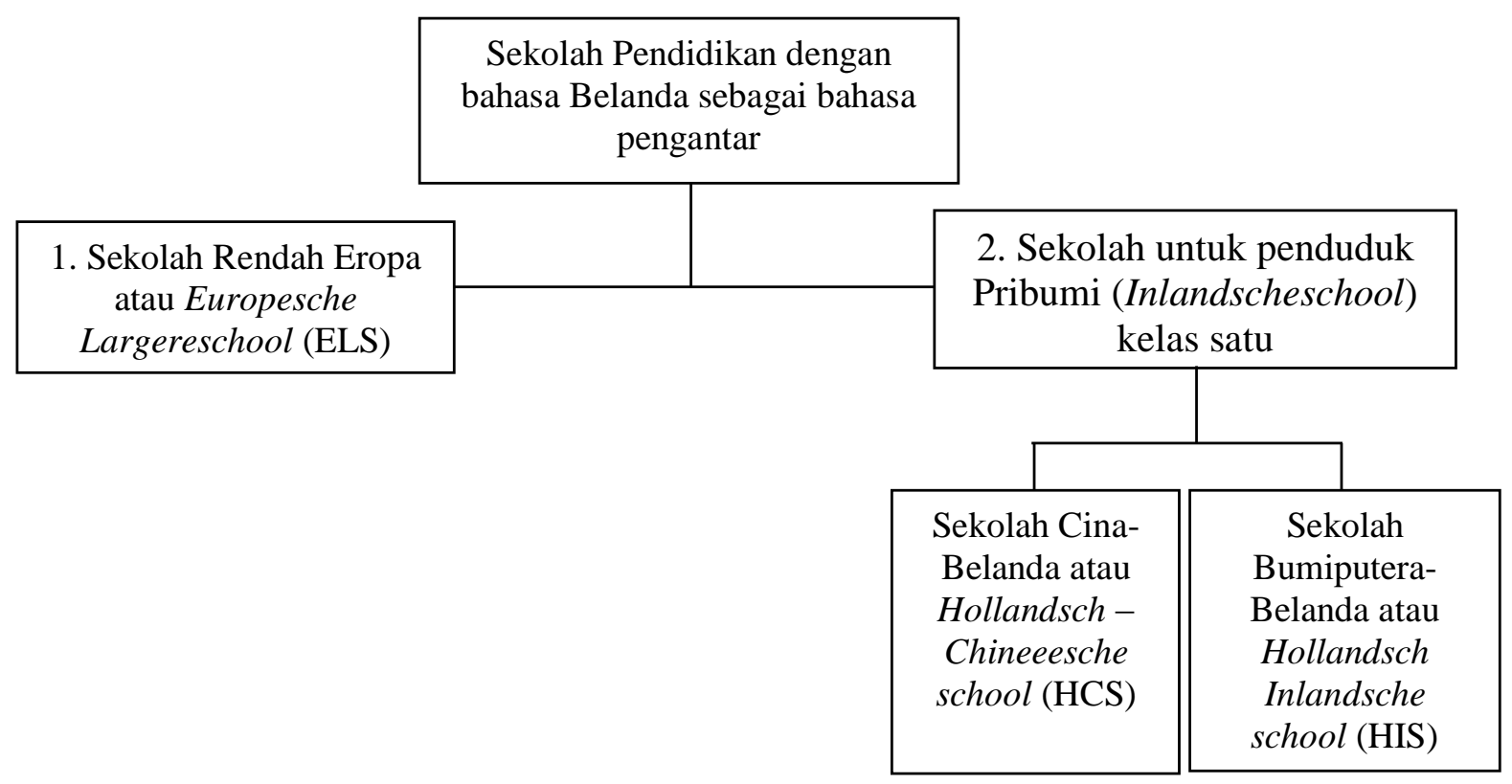

(Sumber: Ekadjati, 1986: 57-60)

Keterangan bagan di atas menggambarkan sistem pendidikan yang digunakan oleh pemerintah Hindia Belanda. Sekolah Kelas ELS, HIS dan HCS menggunakan bahasa Belanda sebagai bahasa pengantar di setiap sekolahnya. HIS merupakan sekolah yang diuntukkan penduduk pribumi kelas I, artinya anak-anak pejabat pemerintah seperti para priyayi dan menak. Sekolah dasar untuk penduduk pribumi atau bumiputra dibagi menjadi dua kategori yaitu Sekolah Dasar Kelas Satu (De Scholen der Eerste Klasse) untuk HIS dan Sekolah Dasar Kelas Dua (De Scholen der Tweede Klasse) untuk sekolah pribumi, sekolah desa. Sekolah Dasar Kelas Satu didirikan di ibu kota keresidenan, kabupaten, kewedanaan. Sekolah Dasar kelas satu diperuntukkan bagi anak-anak golongan atas, seperti golongan bangsawan, 
tokoh-tokoh terkemuka, dan orang-orang bumiputra yang terhormat (Herlina, 2013: 12).

Sekolah Dasar Kelas Dua dibuka untuk memenuhi kebutuhan pendidikan bagi masyarakat umum. Sekolah Kelas Dua memang diperuntukkan penduduk pribumi guna mendidik calon-calon pegawai rendah. Hal ini diperlihatkan dengan bahasa pengantar di Sekolah Kelas Dua ini menggunakan bahasa daerah. Sekolah kelas dua dibagi menjadi 4, di antaranya adalah:

1) Sekolah Bumiputra (Inlandscheschool) kelas dua:

Sekolah ini belajarnya 5 tahun diperuntukan anak-anak penduduk pribumi golongan menengah.

2) Sekolah Desa (Volkschool):

Sekolah ini didirikan tahun 1907 dan diperuntukan anak-anak rakyat biasa yang tinggal di desa-desa. Lama belajarnya 3 tahun. Biaya sekolah ini ditanggung oleh pemerintah. Pengetahuan yang diajarkan hanyalah sekadar kepandaian membaca, menulis, dan berhitung.

3) Sekolah Lanjutan (Vervolgschool):

Sekolah ini merupakan sekolah lanjutan dari Sekolah Desa (Volkschool). Lama belajarnya 3 tahun dan diperuntukan murid-murid Sekolah Desa yang berprestasi baik. Sekolah ini hampir berada di setiap Kabupaten di Jawa Barat termasuk Bandung dan Sukabumi.

4) Sekolah Peralihan (Schakelschool):

Sekolah ini didirikan pada tahun 1921 di Bandung. Sekolah peralihan ini diperuntukan murid-murid dari Sekolah Desa 3 tahun yang berbahasa daerah ke sekolah dasar yang berbahasa pengantar bahasa Belanda. Lama belajar 5 tahun" (Ekadjati, 1986: 57-60).

Perbedaan antara Sekolah Kelas Satu dan Sekolah Dua terletak pada lama belajar, kurikulum, tenaga pengajar, dan biaya sekolah. Lama belajar di Sekolah Kelas Dua ini adalah 5 tahun. Sekolah ini didirikan di distrik-distrik atau kewedanaan-kewedanaan sehingga disebut juga Sekolah Distrik (Herlina, 2013: 13-14). Sistem tahapan pendidikan selanjutnya adalah Pendidikan Lanjutan. Pendidikan lanjutan sebelum kebijakan etis sangatlah jarang. Adapun pendidikan lanjutan Gymnasium Willem III yang dibuka di Jakarta hanya diperuntukkan orangorang Eropa. Awal abad ke-20 pendidikan lanjutan akhirnya terbuka untuk penduduk pribumi. Beberapa sekolah lanjutan yang berbahasa pengantar bahasa Belanda, adalah :

1) Meer Uitgebreid Lager Onderwiijs (MULO)

2) Algemeene Middelbareschool (AMS)

3) Horgere Burgereschool (HBS)

Pendidikan Kejuruan yang didirikan di Jawa Barat di antaranya adalah. Sekolah Perkebunan (Cultuurschool) didirikan di Bogor kemudian dipindahkan ke Sukabumi, Sekolah Pertanian Menengah Atas (Middelbare Landbouw School). Ketiga sekolah Landbouwschooltjes. Desa Landbouwschooltjes didirikan di Soreang sekitar tahun 1910. Pemerintah membuka sekolah-sekolah kejuruan itu rupanya atas dasar pertimbangan bahwa tanah/daerah Tatar Sunda sangat subur sehingga perlu adanya tenaga-tenaga yang terdidik untuk mengolahnya (Herlina, 2013: 43). Jenjang pendidikan selanjutnya dalam tahapan pendidikan yang diperuntukkan penduduk pribumi adalah pendidikan tinggi. Pada awalnya pendidikan tinggi tidak ada yang diperuntukkan bagi penduduk pribumi, akan tetapi pada tahun 1920, didirikanlah sekolah tinggi teknik di Bandung Technische Horgere School (THS), Rechts Hogeschool (RHS) sekolah tinggi hukum, dan sekolah kedokteran.

Tabel : Jenjang Pendidikan Hindia Belanda Tahun: 1907-1927

\begin{tabular}{|c|c|c|c|c|c|}
\hline \multirow[b]{2}{*}{ No } & \multicolumn{2}{|c|}{$\begin{array}{c}\text { Sekolah Rendah Europesche } \\
\text { Largereschool (ELS) }\end{array}$} & \multirow{2}{*}{$\begin{array}{l}\text { Sekolah } \\
\text { Lanjutan }\end{array}$} & \multirow{2}{*}{$\begin{array}{l}\text { Sekolah } \\
\text { Tinggi }\end{array}$} & \multirow{2}{*}{$\begin{array}{l}\text { Tahun } \\
\text { Berdir }\end{array}$} \\
\hline & $\begin{array}{c}\text { Berbahasa } \\
\text { Pengantar Bahasa } \\
\text { Daerah Kelas II }\end{array}$ & $\begin{array}{c}\text { Berbahasa } \\
\text { Pengatar Bahasa } \\
\text { Belanda Kelas I }\end{array}$ & & & \\
\hline 1. & $\begin{array}{l}\text { Sekolah Desa } \\
\text { (Volkschool) }\end{array}$ & & & & 1907 \\
\hline 2. & Vervolgschool & & & & 1914 \\
\hline 3. & & $\begin{array}{l}\text { Hollandsch - } \\
\text { Chineesche } \\
\text { school }(\mathrm{HCS})\end{array}$ & & & 1908 \\
\hline
\end{tabular}




\begin{tabular}{c|l|l|l|l}
4. & $\begin{array}{l}\text { Hollandsch } \\
\text { Inlandsche } \\
\text { school (HIS) }\end{array}$ & & & 1914 \\
\hline 5. & Sekolah Peralihan (Schakleschool) & & & 1921 \\
\hline 6. & & MULO & & 1914 \\
\hline 7. & & AMS & & 1919 \\
\hline 8. & & HBS & & \\
\hline 9. & & & THS & 1920 \\
\hline 10. & & & RHS & 1924 \\
\hline 11. & & $\begin{array}{l}\text { Sekolah } \\
\text { Kedokteran }\end{array}$ & 1927
\end{tabular}

(Sumber: Ekadjati, 1986: 57-66).

Sistem pendidikan yang dikelola oleh Pemerintah kolonial Hindia Belanda di Bandung dan Sukabumi pada tahun 1800 sudah dilaksanakan oleh Daendels. Namun kemajuan sistem pemerintahan bidang pendidikan di Bandung masih berjalan lambat, perhatian pemerintah kemudian semakin besar ketika politik etis telah digulirkan dan dilaksanakan. Hal ini menjadi dasar dari kebijakan politik etis ini adalah tujuan meningkatkan kehidupan penduduk pribumi. Minat penduduk pribumi untuk sekolah setiap tahunnya selalu meningkat. Sekolah yang didirikan di Bandung yang dibuat untuk golongan ménak disebut Hoofdenschool. Pemerintah kolonial Hindia Belanda membuat sekolah tingkat menengah untuk mendidik calon-calon pegawai pribumi rendah. Sekolah itu disebut "Sekolah Pamong Praja". Pada tahun 1900, sekolah itu berubah menjadi OSVIA "Opleidingschool voor Inlandsche Ambtenaren" Sekolah Pendidikan Calon Pegawai Bumiputera" (Herlina, 2013b: 206). Pemerintah membebaskan kewajiban membayar uang sekolah. Hal ini dikarenakan anggaran pertama untuk pendidikan penduduk pribumi sebesar 25.000 gulden yang ditentukan pada tahun 1848 dan sekolahsekolah baru dibuka pada tahun 1880 (Lombard, 2008: 111). Kemdian perembangan sekolah di Bandung pada akhi abad ke-19 dapat dilihat dari grafik perkembangan sekolah di bawah ini.

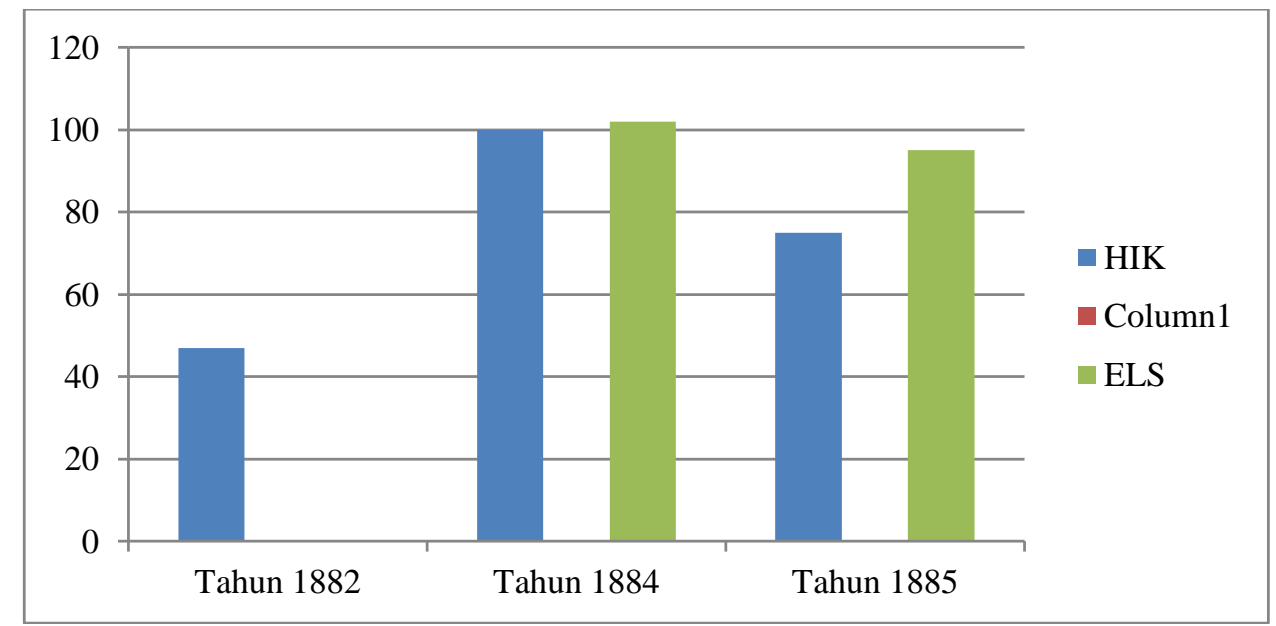

Grafik: Perkembangan Sekolah di Bandung tahun 1882-1886

Keterangan :

Tahun 1882 : HIK (47 Siswa)

Tahun 1884 : HIK (100 Siswa)

: ELS (102 Siswa)

Tahun 1885 : HIK (75 Siswa)

: ELS (95 Siswa)

(Sumber: Hardjasaputra, 2002: 266) [ebook]. 


\section{PENUTUP}

Pendidikan adalah alat pembebasan, pendidikan adalah jalan utama menuju kemerdekaan nasional. Sejarah Pendidikan adalah bagian penting dalam periode pergerakan nasional. Awal abad ke-20 sampai ke pertengahan tahun 1900, gerakan dari para intelektual penduduk pribumi yang membentuk organisasi pergerakan nasional berjuang secara politik dan ideologi melawan sistem pemerintahan kolonial Hindia Belanda. Pendidikan yang dijalankan oleh pemerintah Hindia Belanda pada prinsipnya hanya bertujuan untuk kepentingan kolonial. Penduduk pribumi tidak mendapatkan pendidikan tinggi. Penduduk pribumi hanya dididik agar bisa membaca dan menulis saja. Hal ini dimaksudkan agar pemerintah kolonial dapat mencetak tenaga murah yang digunakan sebagai alat untuk mempertahankan status quo pemerintah kolonial. Setiap penduduk pribumi yang terdidik sebagian besar mengabdi kepada kepentingan pemerintah kolonial. Perubahan berangsurangsur terjadi, sifat pendidikan yang hanya mencetak tenaga murah kemudian berubah setelah politik etis dilaksanakan. Pada saat bergulirnya kebijakan politik etis pokok-pokok pikiran mengenai pendidikan dan pengetahuan barat diterapkan kepada penduduk pribumi dan menggunakan Bahasa Belanda untuk Bahasa pengantara di setiap sekolah-sekolah kelas 1 .

Pendidikan kelas dua hanya diperuntukan kalangan penduduk pribumi disesuaikan dengan kebutuhan mereka saja. Pendidikan untuk kelas 1, dilakukan agar penduduk pribumi di Hindia Belanda bisa menduduki tempat-tempat yang diduduki oleh orang-orang Belanda. Para founding father Indonesia adalah kalangan terdidik yang sadar akan situasi dan kondisi rakyat Indonesia yang terjajah. Hal ini dikarenakan terdidiknya kalangan bumiputra dan berhasil meraih kemerdekaan secara utuh. Maka, dengan terdidiknya penduduk pribumi, lahirlah beberapa organisasi-organisasi pergerakan nasional. Perjuangan menuju kemerdekaan akhirnya menemukan babak baru setelah pentingnya pendidikan bagi rakyat di Hindia Belanda, yaitu perjuangan politik. Perjuangan yang tidak menggunakan senjata untuk menuju kemerdekaan.

\section{DAFTAR PUSTAKA}

Anrooij, Fv. [terj: Nurhayu W.S \& Susi M]. 2014. De Koloniale staat, 1854-1942; Leiden. Nationaal Arcief.

Breman, J. 2014. Keuntungan Kolonial dari Kerja Paksa, Sistem Priangan dari Tanam Paksa Kopi di Jawa 1720-1870. Jakarta: Yayasan Pustaka Obor Indonesia.

De Haan, F. Priangan: de PreangerRegentschappen onder het Nederlandsch bestuur tot 1811. Batavia: Kolff. 'sGravenhage' Nijhoff.

Enklaar. De Preanger Regentschappen: Maschappij tot nut van den Javaan 5.

Ekadjati, E.S. 1986. Sejarah Pendidikan Daerah Jawa Barat. Departemen Pendidikan dan Kebudayaan: Proyek Inventarisasi dan Dokumentasi Kebudayaan Daerah.

Falah, M. 2010. Sejarah Kota Tasikmalaya, 1820-1942. Bandung: Uga Tatar Sunda bekerja sama dengan Yayasan Masyarakat Sejarawan Indonesia Cabang Jawa Barat.

Furnivall, J.S. 1948. Colonial Policy and Practice. Cambridge.

Garraghan. G.J.S.J. 1957. A Guide to Historical Method Vol I \& Vol II. Fordham University Press: New York.

Gottschalk, L. 2008. Mengerti Sejarah. Jakarta: Universitas Indonesia Press.

Hardjsaputra. S. A. 2002. "Perubahan Sosial di Bandung 1810-1906. Disertasi. Depok: PPS Universitas Indonesia [ebook].

Herlina, N et al. 2013. Sejarah Provinsi Jawa Barat Jilid 2. Bandung: Yayasan Masyarakat Sejarawan Indonesia (YMSI) Cabang Jawa Barat.

Kartodirdjo. S. 2014. Pengantar Sejarah Indonesia Baru: Sejarah Pergerakan Nasional Dari Kolonialisme sampai Nasionalisme. Jilid 2. Yogyakarta: Penerbit Ombak.

Multatuli. [terj: Andi Tenri W]. Max Havelaar. Yogyakara: Penerbit Narasi.

Nasution. 1987. Sejarah Pendidikan Indonesia. Bandung: Penerbit Jemmars.

Ricklefs. M.C. 2008. Sejarah Indonesia Modern 1200-2008. Jakarta: Serambi Ilmu Semesta.

Sartre. J.P. [terj: Murtanto]. 2002. Eksistensialisme \& Humanisme. Yogyakarta: Pustaka Pelajar.Kolonial Verslag: Als Bijlage $C$ van Verslag der Handelingen 
Yadi Kusmayadi

Sejarah Perkembangan Pendidikan di Priangan 1900-1942

van de Tweede Kamer deer Staten-

General. Jaar 1869-1870. 
Jurnal Artefak:

History and Education, Vol.4 No.2 September 2017

Halaman | 152 